
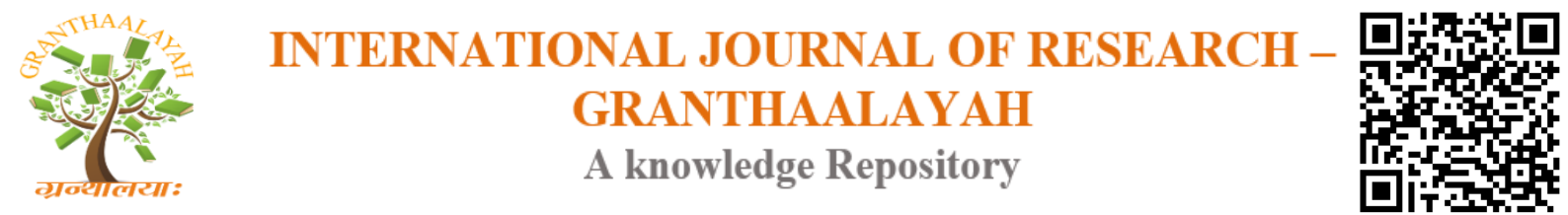

Science

\title{
STUDY OF SOME POLYCYCLIC AROMATIC HYDROCARBONS POLLUTION IN ROADSIDE SOIL AT MORENA, INDIA
}

\author{
Laxmi Kant Sharma *1 \\ ${ }^{* 1}$ Department of Chemistry, Ambah Post Graduate College Ambah, MORENA - 476111, India
}

\begin{abstract}
Study of some polycyclic aromatic hydrocarbons pollution in roadside soil was conducted in developing city during winter, summer, monsoon season to ascertain the contamination levels and their distribution behavior in soil. The concentration of polycyclic aromatic hydrocarbons was determined at nine locations of Morena in India at roadside, residential and agricultural in soil covering all the major traffic intercepts within city.
\end{abstract}

Keywords: Polycyclic Aromatic Hydrocarbons (PAHs); Roadside Soil Pollution; Gas Chromatography; Morena.

Cite This Article: Laxmi Kant Sharma. (2017). "STUDY OF SOME POLYCYCLIC AROMATIC HYDROCARBONS POLLUTION IN ROADSIDE SOIL AT MORENA, INDIA.” International Journal of Research - Granthaalayah, 5(11), 109-115. https:// doi.org/10.29121/granthaalayah.v5.i11.2017.2334.

\section{Introduction}

Motor vehicles are thought to be the major source of atmospheric polycyclic aromatic hydrocarbons (PAHs). PAHs occur in particles [1] or in the vapour phase and are often emitted into the atmosphere [2-3]. The impact of automobile emissions on environment, predominantly on soil, air and water is increasing day by day. Automobile emissions have shown a tremendous impact on the environment during the past few years [4]. PAHs concentration in road soil was found to vary according to distance from the source of origin. Once such PAHs seep into the soil, they got accumulated in horizons rich in organic matter, where they are likely to be retained for many years due to their persistence, hydrophobicity and slow degradation [5]. PAHs have been documented to cause several health problems [6]. Some PAHs and their derivations are highly toxic in nature [7-8]. Reduction of industrial emissions of volatile organic compounds (VOCs) is a part of a global strategy to reduce pollution [9-10].

Roadside soil is one of the closed sink for automobile generated PAHs. They are deposited in soil after condensation and adsorption on particulate matter (soot or dust particle) in the air. It is a good indicator of pollution and environmental risk to human as it is continuously accumulated in soil from where it may come in human contacts in various ways depending upon seasons. 
Soils are an important reservoir for these compound [11] and exchanges between soils and atmosphere is a widely studied process [12]. The average concentration of all PAHs was 6838.6 $\pm 3528.4 \mu \mathrm{g} / \mathrm{kg}$. The concentration of carcinogenic PAHs was found to be $67.4 \%$ out of total PAHs estimated [13]. The maximum PAH concentrations were measured in urban soils, followed by rural village soils and soils from remote locations [14]. The fluoranthene, benzo(b)fluoranthene and benzo(a)pyrene were found in higher concentration [15].

The present study is to determine the concentration, type, statical analysis of the results, distribution pattern and behaviour of PAHs during winter, summer and monsoon season in the roadside, residential and agricultural site of Morena, India.

\section{Experimental}

\subsection{Materials and Methods}

Morena is located at $26.30^{\circ} \mathrm{N} 78.00^{\circ} \mathrm{E}$. Geographically Morena is an interesting place as Madhya Pradesh touches two neighbouring states i.e. Rajasthan and Uttar Pradesh here. Morena touches Dholpur (Rajasthan) in North-West and Pinahat (Agra, Uttar Pradesh) in North-East. Morena is fifth district in state in density of population after Bhopal, Indore, Jabalpur, and Gwalior. The district has a widely dispersed population of 1,965,137 as of 2011. It has an average elevation of 177 metres (580 feet). Morena's climate is classified as warm and temperate. The average temperature in Morena is $25.8^{\circ} \mathrm{C}$. The rainfall here averages $879 \mathrm{~mm}$.

Nine sampling locations were chosen on the basis of high traffic density, urban populations and geographical dispersion. Sampling sites were Porsa Chouraha (L1), MS Chouraha (L2), Banmore (L3), [Roadside site], MLD Colony (L4), Jiwaji Nagar (L5), Housing Board Colony (L6), [Residential site], Badfara (L7), Khurd (L8), Mudiyakhera (L9), [An Agricultural site]. Table 1: Sampling sites of study area.

The soil samples were collected during winter (November-February), summer (March-June) and monsoon (July-October). A total of 27 samples were collected from nine locations (L1-L9). From each sampling location three soil samples were collected from roadside, residential and agricultural in (winter, summer and monsoon season). Samples were collected from $6 \mathrm{~cm}$ below the surface layer. The bulk samples collected from sites were stored in polyethylene bags and brought to laboratory. Stones, leaves, debris and other extraneous materials were sieved out before analysis. All the samples were dried in a hot air oven maintained at $40-60{ }^{\circ} \mathrm{C}$ for 24 hour for removal of free moisture. The samples were preserved in desiccators and stored in dark before extraction. Analytical grade reagents, solvents and standards used in the study were procured from Merck specialty Chemicals, Pvt. Ltd. Mumbai, India. PAH standards used in GC studies were procured from Dr. Ehrenstorfer GmbH Chemicals, Merck, Germany. All glasswares of Borosil make glass (A grade) were used in the study. Glasswares were dipped in dilute nitric acid and washed with plain and double distilled water every time before use. Polycyclic aromatic hydrocarbons present in the samples were analyzed on Nucon make microprocessor based gas chromatograph, (Model No 5765) using RH-5 capillary column (30 m length, $0.53 \mathrm{ID} \times 3.0 \mu \mathrm{m}$ ). Rotavapor and soxhlet extraction assemblies were used for extraction of PAHs from the soil samples. 
About $20 \mathrm{~g}$ of pre dried soil samples were heated at $40-60{ }^{\circ} \mathrm{C}$ to remove any trace of moisture before extraction. Dried soil samples were transferred in soxhlet apparatus and extracted using acetone and dichloromethane (1:1 ratio) as solvents at the rate of 3 cycles/h for $8 \mathrm{~h}$. The extract was allowed to cool and filtered through a Whatman filter paper No. 41. The filtrate was concentrated to $1 \mathrm{~mL}$ volume using rotary evaporation at $60{ }^{\circ} \mathrm{C}$ under gentle vacuum. Extract were finally filtered through micro silica gel column of $6 \mathrm{~cm}$ length to remove impurities. The extracts collected were preserved in amber coloured sample tubes and stored in refrigerator below $4{ }^{\circ} \mathrm{C}$ till analysis was carried out. Samples were later analyzed for types and concentration of PAHs by GC.

Table 1: Sampling sites of study area

\begin{tabular}{|c|c|c|c|c|}
\hline S.NO. & LOCATION ID & LOCATIONS & & SITES \\
\hline 1 & L1 & PORSA CHOURAHA & $\longrightarrow$ & ROADSIDE \\
\hline 2 & $\mathrm{~L} 2$ & MS CHOURAHA & & ............,,,,............... \\
\hline 3 & L3 & BANMORE & & ............, \\
\hline 4 & L4 & MLD COLONY & $\longrightarrow$ & RESIDENTIAL \\
\hline 5 & L5 & JIWAJI NAGAR & & ............, $, 9, \ldots . . . . . . . . . .$. \\
\hline 6 & L6 & HOUSING BOARD COLONY & & ...........,,,,$\ldots . . . . . . . . . .$. \\
\hline 7 & L7 & BADFARA & $\longrightarrow$ & AGRICULTURAL \\
\hline 8 & L8 & KHURD & & ............,,,,,.............. \\
\hline 9 & L9 & MUDIYAKHERA & & ............, \\
\hline
\end{tabular}

\section{Results and Discussion}

The results of concentration of PAHs determined in 27 soil samples during winter, summer and monsoon at roadside, residential and agricultural soil has been shown in Table-2, 3, and 4. Nine sampling location were divided into high/average population and traffic density areas. In present study, 13 EPA identified PAHs namely NAP- Napthalene, ACY- Acenapthylene, ACEAcenapthene, FLU- Fluorene, PHE- Phenanthrene, ANT- Anthracene, FLT- Fluoranthene, PYRPyrene, B(a)A- Benzo(a)anthracene, CHR- Chrysene, B(b)F- Benzo(b)fluoranthene, B(k)FBenzo(k)fluoranthene, B(a)P-Benzo(a)pyrene, B(ghi)P- Benzo(ghi)pyrelene were determined.

The average concentration and types of PAHs at various intercepts were found to differ from place to place. Seasonal concentration of PAHs detected at various locations (roadside, residential and agricultural) are shown in Fig. 1(a),(b), and (c). The average observed PAHs value was highest in roadside soil $11.83 \mathrm{mg} \mathrm{kg}^{-1}$ (L3), residential $8.07 \mathrm{mg} \mathrm{kg}^{-1}$ (L5) and agricultural $6.35 \mathrm{mg} \mathrm{kg}^{-1}$ (L7), respectively. The roadside site had the highest total PAH concentration followed by residential and agricultural site. High concentration at roadside may be because of very intense automobile traffic about $10^{5}$ vehicles per day. In all the sites chrysene and benzo(b)fluoranthene were the predominant compounds. This might be due to industrial-oil burning, wood combustion and emission coming from diesel powered vehicles [16]. Summarizes the seasonally averaged concentrations of all measured PAH in soil at three sites; i.e. roadside, residential and agricultural. The average concentrations of PAH in winter, summer and monsoon are dominating in roadside area i.e. 9.97 (L1), 11.46 (L2) and 11.83 (L3) $\mathrm{mg} \mathrm{kg}^{-1}$ respectively, whereas the lowest concentrations PAH are formed to be in agricultural area i.e. 6.35 (L7), 5.33 (L8) and 5.22 (L9) $\mathrm{mg} \mathrm{kg}^{-1}$, respectively. The concentrations of PAH in residential sites were 
found to be 7.3 (L4), 8.07 (L5) and 6.86 (L6) $\mathrm{mg} \mathrm{kg}^{-1}$. Temperature of soil is a very important factor in determining the leachability or mobility of soil PAH.

Table 2: Concentration of PAHs at different locations of Morena in Winter Season $\left(\mathrm{mg} \mathrm{kg}^{-1}\right)$

\begin{tabular}{|c|c|c|c|c|c|c|c|c|c|}
\hline \multirow[t]{3}{*}{ PAHs } & \multicolumn{9}{|c|}{ LOCATIONS } \\
\hline & \multicolumn{3}{|c|}{ ROADSIDE } & \multicolumn{3}{|c|}{ RESIDENTIAL } & \multicolumn{3}{|c|}{ AGRICULTURAL } \\
\hline & L1 & $\mathbf{L 2}$ & $\mathbf{L 3}$ & L4 & L5 & L6 & L7 & L8 & L9 \\
\hline NAP & 1.05 & 0.98 & 1.72 & 0.76 & 0.62 & 0.78 & 0.64 & 0.42 & 0.46 \\
\hline ACY & 0.52 & 1.65 & 0.96 & 0.34 & 0.46 & 0.25 & 0.57 & 0.65 & 0.54 \\
\hline ACE+FLU & 0.56 & 0.97 & 0.86 & 0.45 & 1.24 & 0.88 & 0.68 & 0.42 & 0.58 \\
\hline PHE & 0.46 & 0.82 & 0.67 & 0.64 & 0.72 & 0.68 & 0.17 & 0.26 & 0.35 \\
\hline ANT & 0.74 & 1.46 & 1.56 & 0.57 & 0.87 & 0.57 & 0.4 & 0.46 & 0.56 \\
\hline FLT & 0.86 & 1.42 & 0.56 & 0.84 & 1.32 & 0.94 & 0.6 & 0.36 & 0.78 \\
\hline PYR & 1.12 & 0.92 & 0.84 & ND & ND & ND & ND & ND & ND \\
\hline $\mathbf{B}(\mathbf{a}) \mathbf{A}$ & 0.58 & 1.03 & 0.96 & 0.48 & 0.64 & 0.35 & 0.3 & 0.21 & 0.28 \\
\hline CHR & 1.65 & 1.76 & 2.21 & 0.85 & 1.02 & 1.35 & 1.26 & 1.24 & 0.76 \\
\hline $\mathbf{B}(\mathbf{b}) \mathbf{F}$ & 1.15 & 0.84 & 1.65 & 0.74 & 0.95 & 0.68 & 0.95 & 0.65 & 0.38 \\
\hline $\mathbf{B}(\mathbf{k}) \mathbf{F}$ & 0.46 & 0.25 & 0.41 & ND & ND & ND & ND & ND & ND \\
\hline $\mathbf{B}(\mathbf{a}) \mathbf{P}$ & 0.56 & 0.38 & 0.65 & ND & ND & ND & ND & ND & ND \\
\hline B(ghi)P & 0.63 & 0.62 & 0.62 & 0.34 & 0.52 & 0.38 & 0.57 & 0.26 & 0.35 \\
\hline TOTAL & 10.34 & 13.1 & 13.67 & 6.01 & 8.36 & 6.86 & 6.14 & 4.93 & 5.04 \\
\hline
\end{tabular}

Table 3: Concentration of PAHs at different locations of Morena in Summer Season $\left(\mathrm{mg} \mathrm{kg}^{-1}\right)$

PAHs

\begin{tabular}{llllllllll} 
& \multicolumn{3}{c}{ ROADSIDE } & \multicolumn{3}{c}{ RESIDENTIAL } & \multicolumn{3}{c}{ AGRICULTURAL } \\
\hline NAP & L1 & L2 & L3 & L4 & L5 & L6 & L7 & L8 & L9 \\
ACY & 0.45 & 1.32 & 1.62 & 0.72 & 1.75 & 0.65 & 0.54 & 0.32 & 0.36 \\
ACE+FLU & 0.94 & 0.76 & 0.32 & 0.48 & 0.36 & 0.67 & 0.45 & 0.65 & 0.65 \\
PHE & 0.68 & 0.36 & 0.68 & 0.71 & 0.46 & 0.71 & 0.24 & 0.23 & 0.26 \\
ANT & 0.82 & 1.25 & 1.12 & 0.85 & 0.65 & 0.83 & 0.65 & 0.62 & 0.47 \\
FLT & 0.65 & 0.98 & 0.56 & 1.21 & 0.72 & 0.35 & 0.64 & 0.26 & 0.36 \\
PYR & 1.45 & 0.72 & 0.64 & ND & ND & ND & ND & ND & ND \\
B(a)A & 0.25 & 0.65 & 0.75 & 0.38 & 0.65 & 0.46 & 0.24 & 0.24 & 0.65 \\
CHR & 1.03 & 1.74 & 0.85 & 0.94 & 1.45 & 0.94 & 1.26 & 0.98 & 0.34 \\
B(b)F & 1.28 & 0.56 & 1.02 & 1.25 & 0.68 & 1.04 & 0.95 & 0.63 & 0.64 \\
B(k)F & 0.35 & 0.45 & 0.76 & ND & ND & ND & ND & ND & ND \\
B(a)P & 0.32 & 0.31 & 0.78 & ND & ND & ND & ND & ND & ND \\
B(ghi)P & 0.56 & 0.34 & 0.65 & 0.45 & 0.42 & 0.32 & 0.56 & 0.46 & 0.25 \\
TOTAL & $\mathbf{9 . 4}$ & $\mathbf{1 0 . 0 8}$ & $\mathbf{1 0 . 1 1}$ & $\mathbf{7 . 6 4}$ & $\mathbf{7 . 7 5}$ & $\mathbf{6 . 2 2}$ & $\mathbf{5 . 8 7}$ & $\mathbf{4 . 8 4}$ & $\mathbf{4 . 6 3}$ \\
\hline & & & & & & & & & \\
\hline
\end{tabular}


Table 4: Concentration of PAHs at different locations of Morena in Monsoon Season $\left(\mathrm{mg} \mathrm{kg}^{-1}\right)$

\section{PAHs}

NAP

ACY

ACE+FLU

PHE

ANT

FLT

PYR

B(a)A

CHR

$\mathbf{B}(\mathbf{b}) \mathbf{F}$

$\mathbf{B}(\mathbf{k}) \mathbf{F}$

$\mathbf{B}(\mathbf{a}) \mathbf{P}$

B(ghi)P

TOTAL

ROADSIDE

L2 L3

0.98

1.24

0.46

1.02

0.82

0.64

0.65

1.26

1.14

0.68

0.65

0.86

1.24

0.75

0.46

1.45

1.45

1.12

0.76

0.47

0.71

$\begin{array}{ll}0.82 & 0.97\end{array}$

1.24

1.74

1.46

1.28

0.65

1.65

0.24

0.35

0.75

0.24

0.24

0.38

0.72

0.36

0.75

10.19

11.2

11.71

\section{LOCATIONS}

\section{RESIDENTIAL}

L4 L5 L6

0.73

1.12

$0.46 \quad 0.65$

0.71

0.54

$0.76 \quad 0.75$

$0.92 \quad 0.65$

$1.26 \quad 0.94$

ND ND

$\begin{array}{ll}0.65 & 0.43\end{array}$

$\begin{array}{ll}0.97 & 1.24\end{array}$

1.03

ND

ND

0.76

8.25

1.04

ND

ND

0.76

8.12
0.96

\section{AGRICULTURAL}

$\begin{array}{lll}\text { L7 } & \text { L8 } & \text { L9 }\end{array}$

$\begin{array}{lll}0.47 & 0.24 & 0.68\end{array}$

0.36

0.76

$\begin{array}{ll}0.62 & 0.72\end{array}$

0.65

0.68

0.46

0.75

0.38

$\begin{array}{ll}0.64 & 0.35\end{array}$

$\begin{array}{ll}0.35 & 0.74\end{array}$

0.68

0.46

$\begin{array}{ll}0.57 & 0.62\end{array}$

$\begin{array}{lll}0.68 & \text { ND } & \text { ND }\end{array}$

$\begin{array}{llll}0.48 & 0.3 & 0.34 & 0.36\end{array}$

$\begin{array}{llll}2.05 & 1.36 & 1.35 & 0.94\end{array}$

$\begin{array}{llll}0.46 & 1.27 & 0.76 & 0.58\end{array}$

ND ND ND ND

ND ND ND ND

$\begin{array}{llll}0.65 & 0.68 & 0.58 & 0.38\end{array}$

$\begin{array}{llll}7.5 & 7.04 & 6.23 & 6\end{array}$

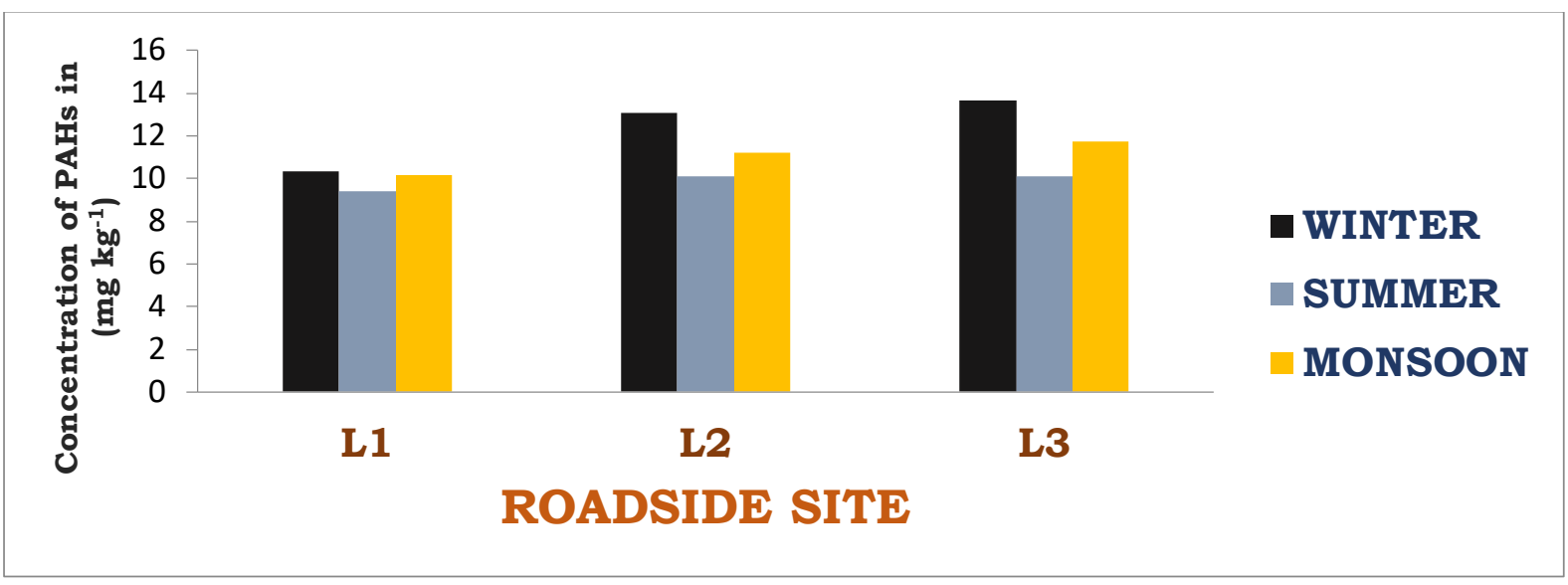

Figure 1(a): Seasonal variation of total PAHs concentration (13 PAHs) in roadside site soil

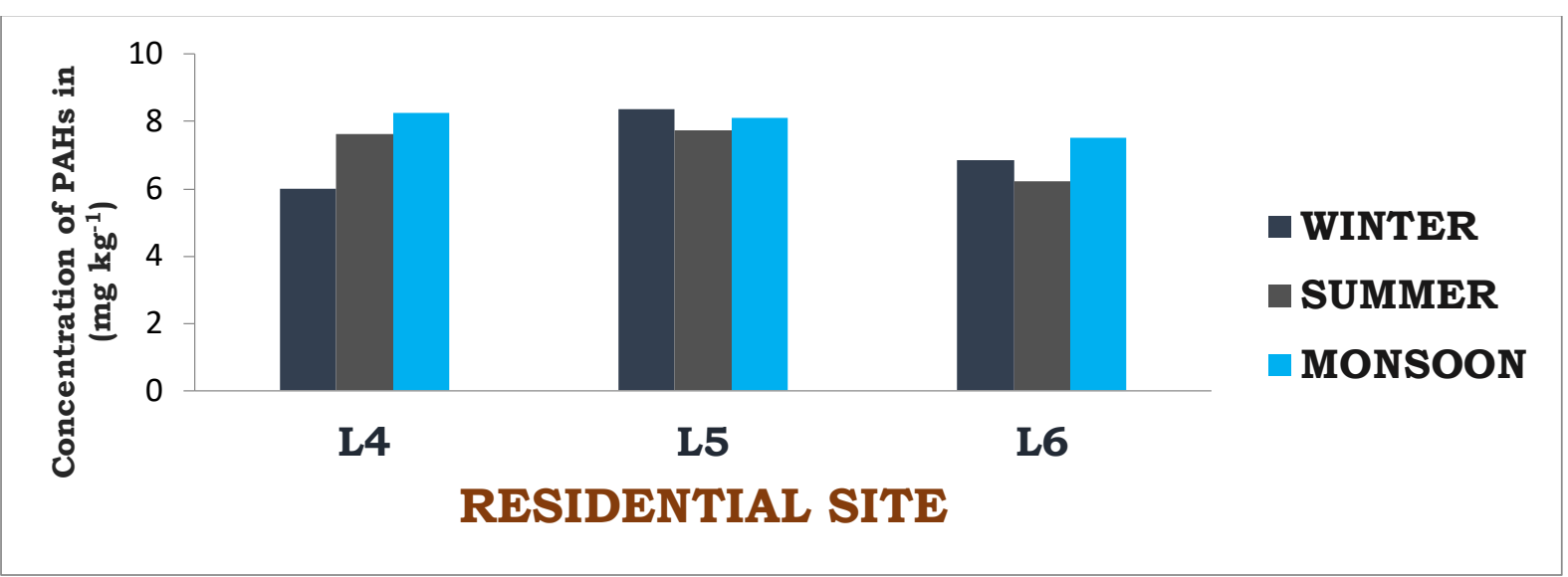

Figure 1(b): Seasonal variation of total PAHs concentration (10 PAHs) in residential site soil 


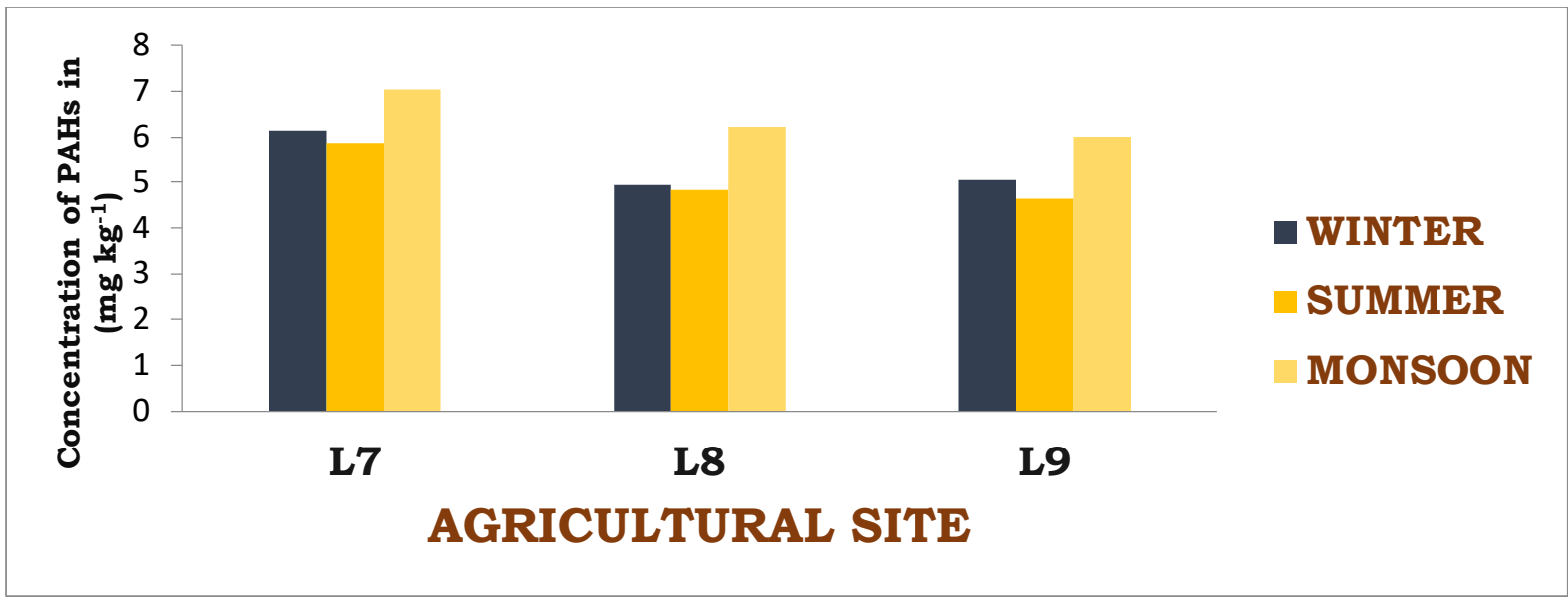

Figure 1(c): Seasonal variation of total PAHs concentration (10 PAHs) in agricultural site soil

\section{Conclusion}

This monograph study of roadside soil is highly contaminated at Morena. It was also concluded from this study that even developing cities are showing equal or even higher concentration of PAHs than metro cities, which is a dangerous sign toward human exposure. The study could be of great significance for the planers while considering environmental remedial measures.

\section{References}

[1] Bodzek, D.; Krystyna, Luks-Betlej; Warzecha, L., "Determination of particle-associated polycyclic aromatic hydrocarbons in ambient air samples from the Upper Silesia region of Poland." Atmos. Environ., 27A (5), 759-764, (1993).

[2] Fromme, H.; Oddoy, A.; Piloty, M.; Krause, M.; Lahrz, T., "Polycyclic aromatic hydrocarbons (PAH) and diesel engine emission (elemental carbon) inside a car and a subway train." Sci. Total Environ., 217 (1-2), 165-173, (1998).

[3] Nielsen, T.; Jorgensen, H. E.; Larsen, J. C.; Poulsen, M., "City air pollution of polycyclic aromatic hydrocarbons and other mutagens: occurrence, sources and health effects." Sci. Total Environ., 189-190, 41-49, (1996).

[4] Kumata, H.; Sanada, Y.; Takada, H.; Ueno, T., "Historical Trends of n-cyclohexyl-2benzothiazolamine, 2-(4- morpholinyl) benzothiazole, and other anthropogenic contaminants in the urban reservoir sediment core.” Environ. Sci. Tech., 34 (2), 246-253, (2000).

[5] Krauss, M.; Wilcke, W.; Wolfgang, Z., "Availability of polycyclic aromatic hydrocarbons (PAHs) and polychlorinated biphenyls (PCBs) to earthworms in urban soils." Environ. Sci. Tech., 34 (20), 4335-4340, (2000).

[6] Zhang, H.; Dang, Z.; Zheng, L. C.; Yi, X. Y., "Remediation of soil co-contaminated with pyrene and cadmium by growing maize (Zea mays L.).” Int. J. Environ. Sci. Tech., 6 (2), 249- 258, (2009).

[7] Okafor, E. Ch.; Opuene, K., "Preliminary assessment of trace metals and polycyclic aromatic hydrocarbons in the sediments." Int. J. Environ. Sci. Tech., 4 (2), 233-240, (2007).

[8] Juang, D. F.; Lee, C. H.; Hsueh, S. C., "Chlorinated volatile organic compounds found near the water surface of heavily polluted rivers." Int. J. Environ. Sci. Tech., 6 (4), 545-556, (2009).

[9] Granström, K. M.; Månsson, B., "Volatile organic compounds emitted from hardwo od drying as a function of processing parameters." Int. J. Environ. Sci. Tech., 5 (2), 141-148, (2008). 
[10] Jafari, H. R.; Ebrahimi, S., “A study on risk assessment of benzene as one of the VOCs air pollution.” Int. J. Environ. Res., 1 (3), 214-217, (2007).

[11] W.A. Ockenden, K. Breivik, S.N. Meijer, E. Steinnes, A.J. Sweetman and K.C. Jones, Environ. Pollut., 121, 75 (2003).

[12] T.F. Bidleman and L.L. McConnell, Sci. Total Environ., 159, 101 (1995).

[13] K. Bhupander, G. Gargi, G. Richa, P. Dev, K. Sanjay, S. C. Shekhar, "Distribution, Composition Profiles and Source Identification of Polycyclic Aromatic Hydrocarbons in Roadside Soil of Delhi, India", J. Environ. Earth Sci., vol. 2, pp. 10-22, (2012).

[14] W. Wang, S. L. M. Smanich, M. Xue, J. Zhao, N. Zhang, R. Wang, J. Cao, S. Tao, "Concentrations, sources and spatial distribution of Polycyclic aromatic hydrocarbons in soils of Beijing, Tianjin and Surrounding areas, North china”, Environ. Poll, vol. 158, pp. 1245-1251, (2010).

[15] D. K. Essumang, K. Kowalski, E. G. Sogaard, "Levels, distribution and source characterization of polycyclic aromatic hydrocarbons (PAHs) in topsoils and roadside soils in Esbjerg, Denmark", Bull. Environ. Contamin. Toxicol., vol. 86, pp. 438-443, (2011).

[16] Ravindra, Mittal, A.K., Grieken, R.V. "Health risk suspended particulate matter with special reference to PAHs: A Review. Reviews on Environmental Health”, 16 (3), 169-189, (2001).

\footnotetext{
*Corresponding author.

E-mail address: laxmikantsharma1984@gmail.com
} 